\title{
A docência administrada: problematizando a questão
}

\author{
Ivair Fernandes de Amorim*
}

Resumo: $O$ texto que se apresenta é fruto das pesquisas realizadas por ocasião do curso de doutoramento e visa à compreensão da inserção de Sistemas Apostilados de Ensino em escolas públicas municipais. Com base em pesquisa empírica e teórica discorre-se sobre o conceito de Docência Administrada, proposto pelo autor, para ilustrar as consequências desta prática sobre a autonomia docente. Tendo como referencial os estudos provenientes de teóricos da Escola de Frankfurt, em especial Herbert Marcuse, propõe uma reflexão crítica sobre a utilização de apostilas, por meio de um estudo de caso, realizado em dois municípios do noroeste paulista, que propiciou dados para as análises realizadas.

Palavras-chave: Sistema apostilado de ensino. Indústria cultural. Autonomia. Docência administrada.

\section{The Administered Teaching: discussing the question}

\begin{abstract}
The present text is a result of the researches done for occasion of the doctorate course and tries to understand the insertion of the Education Systems in municipal public schools. Basing on an empirical and theoretical research it tells about the concept of the Administered Teaching, proposed by the author, with final aim to demonstrate the consequences of this practice on teacher's autonomy. The studies of the theorists from the Frankfurt School, especially Hebert Marcuse, are a reference for this text, enabling the critical reflection about the use of the Education systems, through a case study, carried out in two cities from the northwest of São Paulo State, that provided data for the analyses made.
\end{abstract}

* Doutor em Educação Escolar pela Faculdade de Ciências e Letras da Universidade Estadual Paulista "Júlio de Mesquita Filho" (UNESP). Professor do Ensino Básico Técnico e Tecnológico (EBTT) na Área de Educação/Pedagogia no Instituto Federal de Educação, Ciência e Tecnologia de São Paulo - Campus Votuporanga. E-mail: ivairfernandesamorim@gmail.com. 
Keywords: Education systems. Cultural industry. Autonomy. Administered systems.

\section{La Docencia Administrada: discutindo la cuestión}

Resumen: El Texto que presentase es resultado de las investigaciones desarrolladas por el motivo del curso de doctorado, y todavia tiene la comprensión de la inserción de los sistemas con apostillas de la enseñanza de las escuelas públicas municipales. Con base en investigación empírica y teórica discurre sobre el concepto de docencia administrada, propuesto pr el autor, para la muestra de las consecuencias de esta práctica sobre la autonomia docente. Teniendo como referencial los estudios provenientes de teóricos de la escuela de Frankfurt, en especial Herbert Marcuse, propone una reflexión crítica sobre la utilización de apostillas por medio de un estudio específico, realizado en dos municípios del noroeste paulista, que propició datos para la análisis desarrolladas.

Palabras clave: Sistema con apostillas de la enseñanza. Indústria cultural. Autonomia. Docencia Administrada.

O intuito deste texto é discutir a atividade docente frente à implantação de sistemas apostilados de ensino em escolas públicas municipais. Em virtude das pesquisas realizadas anteriormente, durante a realização do curso de mestrado, partimos da premissa que as apostilas são produtos da indústria cultural ${ }^{1}$ e como tal buscam impor um padrão de consumo e interpretação.

Ao postular desta maneira fomos impelidos ao questionamento de como seria possível o exercício da autonomia docente frente à utiliza-

1 "Tudo indica que o termo indústria cultural foi empregado pela primeira vez no livro Dialektik der Aufklärung, que Horkheimer e eu publicamos em 1947, em Amsterdã. Em nossos esboços tratava-se do problema da cultura de massa. Abandonamos essa última expressão para substituí-la por "indústria cultural”, a fim de excluir de antemão a interpretação que agrada aos advogados da coisa; estes pretendem, com efeito, que se trata de algo como uma cultura surgindo espontaneamente das próprias massas, em suma, da forma contemporânea da arte popular”. (ADORNO, 1987, p. 287). 
ção de sistemas apostilados de ensino. Discutir a autonomia docente é uma tarefa que se insere em um panorama bastante abrangente onde a docência deve ser compreendida como uma atividade profissional que atende a diversas determinações sociais. Esta questão foi discutida no curso de doutorado e as reflexões que aqui se apresentam são advindas desta empreitada.

Vivemos em um contexto em que a utilização de apostilas se sustenta no discurso operacional onde a questão da eficácia das tecnologias educacionais torna-se proeminente em virtude da crescente demanda por instrução escolar imposta pela sociedade industrial.

A este respeito, buscamos embasamento nas discussões da Instrução Programada proposta por Skinner (1972) e nos argumentos de Carnoy (2009) sobre a vantagem acadêmica de Cuba.

Estas reflexões nos remeteram à centralidade para estes autores do exercício de mecanismos de controle que seriam garantidores da qualidade em educação.

Carnoy (2009), em especial, nos impele a refletir sobre a questão da autonomia docente. Para ele a autonomia somente seria benéfica para aquele professor extremamente bem formado. Tentaremos sintetizar a sua fala da forma mais geral.

Ao dizer da educação cubana e do modo como o sucesso educacional é obtido por meio da garantia de que todos alunos aprendam os conteúdos mínimos, por meio de materiais e aulas centralmente controlados, o autor postula que um professor deve dominar perfeitamente todos os conteúdos que ensina, assim como a forma mais eficaz para ensiná-lo. Dessa forma, quanto maior for o número de tópicos dominados pelo docente maior a possibilidade para exercer sua autonomia. Um professor despreparado ao optar, sozinho, por uma determinada metodologia ou por um determinado assunto, pode incorrer na falha de lecionar algo que não sabe e consequentemente ensinar errado.

A autonomia, na visão de Carnoy (2009), consistiria em possuir repertório grande e sólido de conhecimentos que possibilitaria ao mestre 
compor seu próprio currículo de acordo com as necessidades da classe. Ao professor despreparado seria prudente, assim como faz o governo cubano, submeter-lhe um programa pronto e previamente testado, indicando a ele quais os passos a serem dados, assim como a ordem e momento de ministrá-los de modo a garantir que não ocorram equívocos prejudiciais à aprendizagem do educando.

Para nós, porém, a concepção de autonomia de Carnoy (2009) não difere muito da utilização de um menu. O sujeito diante de uma lista de conceitos previamente aprendidos, ou decorados, escolheria quais deveriam ser reproduzidos e em quais momentos. Dessa maneira, a autonomia seria uma questão mais ligada à memorização do que ao raciocínio. O professor seria mais um reprodutor do que um pensador (no sentido literal da palavra).

A autonomia, portanto, se resumiria, pois, ao domínio completo do currículo que se deva ensinar para poder ter a possibilidade de organizá-lo em lições de forma competente.

Diante de nossa realidade acadêmica, esta compreensão se fortalece pelas diversas dificuldades em formar docentes no cenário do Brasil atual. ${ }^{2}$ Com a desvalorização e a precarização da profissão, cresce, em todo território nacional, a falta de licenciados nas mais diversas áreas do conhecimento - fato que fortalece o discurso de que é necessário garantir que os docentes ensinem ao menos os mínimos dos conteúdos de forma correta, sem equívocos.

Neste cenário, as pesquisas que realizamos apontam que a utilização de manuais bastante controladores apresenta-se como alternativa à manutenção da qualidade.

Ainda com base nos dados que coletamos e analisamos, apresen-

2 Tal fato pode ser confirmado inclusive junto aos órgãos governamentais responsáveis pela educação. O site do Ministério da Educação no dia 14/08/2008 já noticiava a preocupação com a falta de professores, em notícia intitulada: "Falta de professores preocupa especialistas", disponível em: $<$ http://portal.mec.gov.br/index.php?option=com_content\&task=view\&id=9885 $>$. Acesso em: 10 maio 2014. 
tamos o argumento que fundamenta a adoção de Sistemas Apostilados de Ensino, a saber: Se nossos professores não possuem boa formação adotamos um material único que determina o conteúdo a ser ensinado, assim como, a sequência e a metodologia com que devem ser abordados. Assim garantiremos que até mesmo aquele docente com formação deficitária exponha a seus alunos um mínimo de conteúdo.

Comprovam esta análise o contato que tivemos com materiais de divulgação de duas grandes editoras: Abril e Positivo, que se dedicam à produção de apostilas para escolas públicas. Estes materiais confirmam a intenção de homogeneizar o trabalho docente por meio do emprego de tecnologias educacionais eficientes.

A editora Abril, por exemplo, ao apresentar o Sistema de Ensino Ser - setor da editora que atua no fornecimento de apostilas para escolas públicas - afirma:

O SISTEMA DE ENSINO SER foi elaborado para atender às necessidades das escolas que buscam levar para as suas salas de aula conteúdos de qualidade, atualizados e de acordo com as diretrizes curriculares nacionais, além de recursos tecnológicos modernos e qualidade ensino.

Aliando a credibilidade das publicações e conteúdo digital do Grupo Abril e a qualidade editorial das Editoras Ática e Scipione, o Sistema de Ensino SER oferece a sua escola um material didático de Educação Infantil ao Ensino Médio, além de serviços e produtos pedagógicos que direcionarão o trabalho do professor em sala de aula (SISTEMA DE ENSINO SER). ${ }^{3}$

Evidencia-se que o material apostilado fornecido busca, juntamente com uma gama de serviços oferecidos como suporte, direcionar o trabalho docente garantindo que trilhem em suas aulas o caminho do sucesso. É

3 O trecho citado faz parte de material de divulgação da Editora Abril intitulado Guia de Informações Pedagógicas que é fornecido às Secretarias Municipais de Educação para divulgação do Sistema Ser de Ensino. Por não possuir informações catalográficas o material impossibilita sua referência bibliográfica. 
preciso reconhecer que uma refutação bastante simples de nossa análise seria a de que os materiais apostilados são adotados apenas como uma orientação, sugestão ou opção disponibilizada ao docente, que na maioria das vezes padece com a falta de materiais didáticos.

No próprio conteúdo que acabamos de citar, o material destinado aos professores é apresentado como uma sugestão.

E para os professores, além dos serviços pedagógicos, o material didático impresso oferece Guia do Professor com quadro de conteúdos do ano letivo, principais objetivos e sugestões de estratégias para cada aula, orientações no decorrer das atividades, sugestões de leitura e aulas complementares e referências bibliográficas (SISTEMA DE ENSINO SER).

Amparados pelo trecho que acabamos de citar, os que advogam pela utilização de apostilas diriam que a adoção deste tipo de material em escolas públicas tem apenas o intuito sugestivo de orientar os docentes e não de impor-lhes um material único.

No entanto, cremos que este discurso eufemizado, que remete a possibilidade de o docente optar ou não pela utilização na íntegra da apostila, está mais ligado ao tipo de organização em que vivemos do que a uma característica própria do material. Ou seja, por não vivermos em um regime autoritário como o de Cuba, mas sim em um ambiente democrático, os Sistemas de Ensino não podem rigidamente ser impostos por um órgão central. Este fato, porém, não indica que a imposição vertical não possa ocorrer em uma sociedade democrática, significa apenas que deve ocorrer de forma diferente. Nas sociedades capitalistas, a solução para questão de como impor padrões tem sido resolvida pelos mecanismos de mercado, ou seja, pelo consumo.

O que queremos evidenciar é que o discurso de que os produtos oferecidos pelas editoras às escolas públicas é apenas uma sugestão flexível que facilite o trabalho do professor é antes uma estratégia de marketing. 
Para impor-se, como mercadoria que são, as apostilas devem seduzir seus consumidores. Este é um ponto importante para nossa tese, vemos que em uma sociedade capitalista o grande ditador é o mercado, e para efetivarem-se como um empreendimento lucrativo, as editoras também devem aderir aos mecanismos de mercado.

O marketing editorial não se acanha em evocar suas características empresariais como a marca. A Editora Abril que tomamos como exemplo usa inclusive desta prerrogativa para conseguir mais parcerias com escolas municipais. Um encarte, que compõe o material promocional da empresa, dedica-se exclusivamente ao marketing educacional. Segundo a editora este é um assunto fundamental.

Pensando nisso, o Sistema de Ensino SER oferece às escolas parceiras uma série de produtos e serviços voltados para a Gestão de Marketing Educacional: são campanhas, informativos em diversas plataformas, pesquisas materiais de divulgação e uma equipe altamente preparada para atender às escolas (SISTEMA DE ENSINO SER).

$\mathrm{Na}$ realidade, as soluções de marketing oferecidas pela editora constituem-se em inúmeras oportunidades para que a escola parceira possa associar sua imagem à marca da empresa contratada. Os produtos oferecidos vão desde a afixação de placas e outdoors na unidade escolar divulgando a utilização do material apostilado da empresa, até a viabilização de propagandas em janelas de ônibus, bonés, camisetas ou caixas de pizza sextavadas. Entendemos, portanto, que esta valorização de um marketing direto e ostensivo corrobora na qualificação das apostilas como mercadorias.

Outro indício de que os mecanismos de mercado habitam o ambiente educacional por meio da comercialização de apostilas é a opção das editoras em motivar a compra de seus materiais ao atrelá-los à grandeza e ao sucesso do empreendimento que representam.

No material de divulgação da Editora Positivo podemos ver: 
Trata-se de uma linha educacional completa para sua escola, com soluções pensadas para o melhor aprendizado de seus alunos e que dão todo suporte para a utilização dos livros pelos professores, seja por meio das orientações metodológicas presentes neles, seja pela Assessoria pedagógica que oferecemos.

Para o desenvolvimento dessa gama de materiais, a Editora Positivo conta com um Centro de Pesquisas, no qual trabalham mais de 200 profissionais que elaboram e desenvolvem todas as obras, com o cuidado de ouvir e entender um mercado cada dia mais atualizado e exigente (EDITORA POSITIVO). ${ }^{4}$

Vemos que o discurso acima, com a mudança de apenas algumas palavras poderiam destinar-se à divulgação de qualquer produto. É importante perceber que a propaganda busca o convencimento de que se está consumindo um produto de qualidade, garantida pelo sucesso da empresa que lhe permite ter infraestrutura e profissionais qualificados.

O que queremos evidenciar é que o feito obtido pelo governo cubano por meio do poder central é buscado pelos dirigentes municipais - não podemos precisar se de forma consciente ou não - através de mecanismos de mercado.

Nesse ponto é que gostaríamos de divergir, pois nossa compreensão de autonomia distancia-se da exposta por Carnoy (2009) e, consequentemente, da adotada pelos defensores dos sistemas apostilas. Não obstante às benesses obtidas por se dominar os conteúdos que se ensina, acreditamos que a autonomia não pode ser reduzida à seleção de conteúdos previamente aprendidos, ou a escolha entre três ou quatro atividades complementares apresentadas por um encarte suplementar que acompanhe um material apostilado.

A concepção de autonomia que adotamos é muito mais complexa e remete à natureza do pensamento humano. Nossa noção de autonomia está calcada na concepção kantiana de maioridade e minoridade (KANT,

4 Este material, por destinar-se a divulgação de um produto, apresenta a mesma dificuldade em estabelecer referência bibliográfica que apresentamos em relação à Editora Abril. 
2005), e, por conseguinte, de emancipação e esclarecimento, conceitos estes bem explanados por Adorno e Horkheimer (1985). Assim, tomar o indivíduo esclarecido como aquele que é capaz de julgar pelo seu próprio entendimento é o mesmo que dizer que esclarecido é o sujeito capaz de pensar.

Ouço, agora, porém, exclamar de todos os lados: não raciocineis! O oficial diz: não raciocineis, mas exercitai-vos! O financista exclama: não racioneis, mas pagai! O sacerdote proclama: não raciocineis, mas crede! (Um único senhor no mundo diz: raciocinai, tanto quanto quiserdes, e sobre o que quiserdes, mas obedecei!) Eis aqui por toda parte a limitação da liberdade (KANT, 2005, p. 65).

No excerto acima, Kant está discutindo o exercício livre da razão pública, que segundo ele é a única alternativa para promoção do esclarecimento. Interessa-nos o fato de que pensar não é útil àqueles que pretendem manter o controle. A reflexão kantiana, assim como as diferentes visões sobre mecanismos de controle social nos auxiliam, a concluir que seja o exército, a igreja, as instituições prisionais, os sanatórios, o governo cubano ou os dirigentes municipais ao buscarem exercer e afirmar seu poder acabam por buscar o domínio dos indivíduos controlando suas ações de forma a manter a coesão do grupo e a reprodução da ordem vigente. O exercício efetivo do pensamento é uma ameaça a este propósito.

A liberdade é condição fundamental ao exercício da autonomia. A liberdade de pensar foi bem explanada por Adorno (1995) como a capacidade de autorreflexão crítica. Somente o sujeito que é capaz de voltar-se sobre si mesmo e indagar as diferentes possibilidades de sua ação pode se dizer emancipado.

É nesse ponto que nos distanciamos da compreensão de Carnoy (2009). A experiência cubana pode ser compreendida como uma alternativa eficaz de treinamento. Tanto que os exemplos tomados para afirmar a vantagem acadêmica de Cuba consistem na discussão do melhor desempenho em matemática apresentado pelos alunos deste país. 
É bastante evidente, no entanto, que é possível aprender a operar cálculos, sem, no entanto, jamais tê-los compreendido. É grande o debate entre os matemáticos atuais sobre esta questão. São notórios os frutos de uma educação matemática que se pautou na apreensão decorada da tabuada e de outros algoritmos matemáticos, porém serviu também à mitificação da disciplina como dificultosa e destinada a poucos intelectuais circunspectos e dedicados o suficiente para abranger as complexas formulações teoréticas.

Dessa forma, a autonomia docente é tomada aqui como um processo que extrapola a manipulação de um repertório. É, portanto, a capacidade do professor refletir sobre si mesmo e sua prática e, se necessário, modificá-la e transformá-la de acordo com a necessidade de seus educandos.

Ao partir desta compreensão, buscamos elucidar as características de nossa sociedade tendo por referência as reflexões do teórico frankfurtiano Hebert Marcuse (1978) que propõe que a sociedade industrial conseguiu meios de dominação mais eficazes que quaisquer outros desenvolvidos no passado por administrar os indivíduos por meio da sedução tecnológica em detrimento da força física. Desse modo, nossa hipótese passou a ser a de que a educação por estar socialmente determinada poderia também estar inserida neste ambiente controlado de uma realidade administrada.

A compreensão da teoria proposta por Marcuse nos leva a entender a afirmação de Zuin (2001) de que a todo o momento somos coagidos a exercer atividades ditas livres. E esta máxima é possível porque somos administrados. É com esta compreensão que pudemos pensar na existência de uma docência administrada.

Sendo os docentes agentes inseridos na dinâmica da sociedade industrial e diretamente influenciados por suas ideologias e mecanismos de controle, não estariam, portanto, no bojo de sua atividade profissional, também subjugados pelos mecanismos de administração social? Não estariam sendo induzidos a acreditar que possuem 
autonomia enquanto planejam suas aulas de acordo com o que já foi planejado, decidindo entre este ou aquele conteúdo que já foi predeterminado? Ou seja, será que a autonomia docente não reside unicamente em escolher consumir este ou aquele produto didático previamente industrializado?

Aprofundar um pouco mais estas questões talvez pudesse nos levar ao questionamento de que se ao serem administrados os docentes não se tornam também ferramentas da coesão e do controle sociais. Os professores seriam ao mesmo tempo objetos e veículos de dominação, pois se tornam disseminadores da lógica instrumental.

Retomaremos, neste momento, os dados explanados, por ocasião da escrita da tese de doutoramento que possibilitou esta reflexão. Ao realizar o primeiro instrumento de pesquisa que propusemos para $\mathrm{o}$ trabalho citado, indagamos os docentes quanto à qualidade de diversos itens do material apostilado: Qualidade de Impressão; Seleção de Conteúdos; Organização e Disposição dos Conteúdos; Clareza, Legibilidade e Interpretação; Pertinência e Coerência dos Conteúdos; Nível de Dificuldade dos Conteúdos; Possibilidade de Interação dos Alunos, Suporte Pedagógico e Suporte On-line.

Por tratar-se de um questionário de questões fechadas, os docentes podiam escolher entre quatro opções para avaliar os itens propostos: péssimo, razoável, bom e excelente. Neste questionamento, os itens Qualidade de Impressão e Suporte On-line foram considerados bons. Os demais itens foram avaliados como razoáveis. Para nós, esta avaliação revelou uma insatisfação dos entrevistados com os Sistemas Apostilados de Ensino.

No entanto, um fato revelado pelo segundo instrumento de pesquisa aplicado - um questionário de questões abertas entregue a $20 \%$ da amostra inicial de professores - nos causou curiosidade.

Ao serem indagados na questão número nove do referido questionário sobre a permanência ou não da utilização dos sistemas apostilados de ensino nas escolas municipais, caso thes fosse conferido o poder de 
decisão, os docentes responderam unanimemente que manteriam a utilização das apostilas em suas escolas.

Eis o nosso questionamento: por quais razões os docentes permaneceriam com a utilização de um material que julgam razoável? Por que não o substituiriam por outros recursos que conduzissem o mais próximo, possível, da excelência? Perguntados sobre outros aspectos da utilização de materiais apostilados em escolas públicas os docentes propiciam-nos subsídios para discutir esta questão.

É interessante observar que, mesmo conscientes das falhas e das inconsistências do material apostilado, os docentes julgam que o material apostilado é um norteador do ato educativo e um balizador do trabalho docente.

$O$ fato de o material apostilado apresentar uma esquematização do conteúdo escolar que é apresentado em unidades previamente determinadas com explícitas referências às técnicas e ao tempo necessários à sua execução, é visto pelos professores como um facilitador do trabalho docente.

Podemos dizer que o material apostilado, segundo o exposto pelos professores, é ao mesmo tempo diretriz curricular e manual didático para o trabalho docente nos municípios que o adotam.

Tal situação não é uma característica nova ou singular mediante a utilização de apostilas em escolas municipais. Prado (2008), em sua dissertação de mestrado, analisou a atividade pedagógica em escolas franqueadas, ou seja, em escolas particulares que adotam uma franquia de um determinado sistema apostilado de ensino. Neste trabalho, o pesquisador demonstra que, igualmente aos docentes que entrevistamos, os professores das escolas franqueadas notam limitações em se utilizar o material apostilado. No caso dos docentes abordados por Prado (2008), as principais limitações situam-se na ausência de participação dos docentes na confecção das apostilas e na exacerbada rigidez quanto à disposição dos conteúdos que são volumosos e que devem ser cumpridos em um espaço curto de tempo, impossibilitando que as necessidades da turma sejam trabalhadas de forma mais singularizada. 
O interessante, contudo, é que Prado (2008) também notou que, mesmo possuindo diversas queixas em relação ao material fornecido pela franquia, os docentes entrevistados sentem-se beneficiados pelo uso de apostilas no dia a dia escolar.

Segundo o pesquisador tal situação ocorre porque:

Há uma espécie de homogeneização do trabalho docente que os próprios professores, domesticados pelos discursos fetichizantes da franquia, julgam ser positivo na medida em que consideram as apostilas facilitadoras da prática de ensino, possibilitando que suas aulas sejam aplicadas em unidades diferentes. Tal domesticação destes professores se dá uma vez que a sua atividade docente é revestida pela maneira como a instituição particular franqueada adestra estes profissionais para que trabalhem com o material sistematizado tal como as condições lhe são sugeridas, condicionando-os ao sistema pré-estabelecido franqueado (PRADO, 2008, p. 82).

As explanações de Prado são exemplares para nossa discussão. A partir delas podemos notar que a situação que detectamos na realidade das escolas públicas é similar a das escolas particulares, a saber: os docentes, mesmo detectando inconsistências e incoerências no material apostilado, acreditam que este material didático é benéfico à atividade docente.

No entanto, possuímos uma discordância conceitual em relação à postulação de Prado (2008). Nossa compreensão da realidade que pesquisamos nos leva a refutar a denominação do processo relatado como adestramento. Embora, lexicograficamente a palavra adestrar possa ser sinonímia de doutrinar ou instruir, comumente este termo tem sido empregado mais à domesticação de animais. Ou seja, adestrar, ao menos no imaginário popular, está ligado ao condicionamento de criaturas, que não possuem consciência, a responder de determinada maneira a estímulos padrões previamente assimilados.

No caso da docência, acreditamos que é indevida a utilização do termo adestramento, haja vista a impossibilidade da existência humana desvincu- 
lada de uma consciência, mesmo que seja uma falsa consciência. ${ }^{5} \mathrm{O}$ que a nosso ver ocorre é uma ilusão em que os docentes creem receber benefícios enquanto estão submetidos a instrumentos de controle e dominação.

Zuin (1992) nos auxilia na compreensão deste fato ao discorrer sobre o mito da sereia.

Se por um lado, no mito da sereia, os marinheiros enfeitiçados são conduzidos à morte, no momento em que abandonam o navio e se lançam ao mar; por outro lado, os consumidores fascinados pelo brilho e beleza, absorvem os produtos pseudoculturais obsessiva e compulsivamente, juntamente com os comportamentos associados, na esperança de que ocorra algum tipo de compensação às suas próprias debilidades egóicas. Tanto o mito quanto a Indústria Cultural prometem, mas não cumprem. Com a diferença de que, se no mito, a promessa é quebrada com a morte imediata, na Indústria Cultural, por outro lado, a debilidade física e psíquica é engendrada de forma cruel e gradativa (ZUIN, p. 22, 1992).

Parece-nos que as apostilas acabam por exercerem certa sedução sobre os professores que, embora conheçam as debilidades do material, acabam por acreditar que ele é a melhor alternativa didática frente às dificuldades impostas ao exercício da profissão docente.

Como legítimos produtos da Indústria Cultural, as apostilas realizam promessas tentadoras aos docentes, como as de realizarem o direcionamento dos conteúdos escolares de acordo com uma matriz curricular que propiciará o desenvolvimento individual dos alunos que serão beneficiados por um tratamento eficaz do conhecimento.

5 Inversamente, a perda da consciência em razão das liberdades satisfatórias concedidas por uma sociedade sem liberdade favorece uma consciência feliz que facilita a aceitação dos malefícios dessa sociedade. É o indício de autonomia e compreensão em declínio. A sublimação exige um alto grau de autonomia e compreensão; é a mediação entre o consciente e o inconsciente, entre os processos primários e secundários, entre o intelecto e o instinto, a renúncia e a rebelião. Em suas mais realizadas formas, tais como na obra artística, a sublimação se torna a força cognitiva que derrota a supressão enquanto se inclina diante dela (MARCUSE, 1978, p. 85). 
No entanto, propomos, embasados pelas reflexões de Ramosde-Oliveira (2001), que o ato de ensinar é uma atividade complexa que demanda tempo e envolvimento humano para poder possibilitar o desenvolvimento integral dos jovens educandos. Um material didático, por melhor que seja, não conseguirá por si só garantir o sucesso do processo educacional. Porém, notamos, por meio de nossa pesquisa, que os docentes estão denotando, cada vez mais, características ontológicas do trabalho docente ao material apostilado, situação que confirma a tese de que os produtos da Indústria Cultural reiteram repetidamente promessas que são incapazes de cumprir.

A nosso ver, este é o principal argumento para justificar o fato de que os docentes, mesmo não estando contentes com a qualidade de vários itens dos materiais apostilados, partam em defesa da manutenção do seu uso nas escolas públicas.

Em outras palavras, os docentes, seduzidos pelo marketing educacional que gravita em torno dos materiais apostilados, esperam que a promessa de uma condução curricular eficaz em meio a um ambiente educacional tão atribulado se realize. E constantemente renovam esta esperança ao serem bombardeados pelos apelos do discurso oficial e pela cobrança de familiares que, também seduzidos pela possibilidade de que seus filhos usufruam dos bens antes confinados às elites, passam a atribuir um valor fetichizado ${ }^{6}$ às apostilas.

Somente para explanar esta situação, concedemo-nos a licença de relatar a fala de um colega professor realizada há poucos meses. Segundo este professor, ao realizar a primeira reunião de pais do ano, foi neces-

6 O caráter fetichista da mercadoria não consiste na observação de que a sociedade venera o valor de troca (literalmente como força divina) presente em todos os seus valores de uso. A ressacralização da troca de mercadorias resulta, antes [...] do fato de que o mercado profano perdeu seu ponto de referência, seu ponto profundamente carregado de sentido sacro, sobre o qual o mercado se alicerçou na forma de uma camada eterna. Uma vez que ele se sobressaiu em relação ao outro e se tornou sistematicamente autorreferente, ele assumiu o lugar do sagrado que fora perdido e se transformou em seu sucedâneo (TÜRCKE, 2010, p. 240). 
sário esclarecer que, devidos aos procedimentos licitatórios, o material apostilado demoraria um pouco a chegar para os educandos. Na ocasião, um pai de aluno se pronunciou dizendo que não havia problema, pois enquanto o material não chegasse os professores se encarregariam de "enrolar" o tempo que fosse necessário. Nesta breve passagem, podemos notar que os pais dos alunos, também seduzidos pelos apelos do marketing educacional, já estão desenvolvendo a ideia de que o professor é incapaz de lecionar na ausência do material apostilado.

Com estas postulações, queremos evidenciar que, para nós, o material apostilado mantém-se no ambiente educacional mais em virtude da sedução própria de um produto da indústria cultural do que em decorrência de sua qualidade.

Discorrido sobre este paradoxo, a nosso ver, central, para a compreensão do objeto pesquisado, passemos à análise de aspectos mais pontuais, mas não por isso menos importantes para a compreensão da autonomia docente frente à utilização de apostilas.

Vimos que a compreensão que os docentes possuem dos sistemas apostilados de ensino está intimamente ligada à ideia de currículo. Se compreendermos currículo como "um objeto que cria em torno de si campos de ação diversos, nos quais múltiplos agentes e forças se expressam em sua configuração, incidindo sobre aspectos distintos" (SACRISTÁN, 2000, p. 101), veremos que certamente o material apostilado constituiria uma das forças que atuam sobre o currículo escolar, da mesma forma como qualquer outro material didático. Ao se optar por x ou por y material, seja ele livro didático ou apostila, a escola e os professores estarão expostos à determinada abordagem do conhecimento que possui seus vieses e ideologias.

No entanto, em nossa pesquisa, a recorrência de que a apostila seria o balizador, senão único, mais importante do itinerário curricular que as disciplinas escolares deverão seguir. Esta situação é problemática. Os professores sentem-se beneficiados pela determinação curricular proposta pela apostila, ao considerar que os sistemas apostilados estruturam os 
conteúdos, organizam o conhecimento, selecionam os temas mais adequados a cada ano e, assim, acaba por aceitar que uma parte bastante singular do seu trabalho seja realizada por outrem.

Tentaremos explicitar nossa concepção.

Ao sistematizar o ensino na forma escolarizada, é necessário que existam algumas diretrizes que norteiem o trabalho docente com a finalidade de garantir um mínimo de conteúdos que devem ser assimilados com o intuito de permitir uma identidade educacional nacional, que atenda às necessidades sociais da nação e que garanta o trânsito do discente entre as unidades escolares no decorrer do ano letivo.

No cenário nacional, estas diretrizes são expressas nos Parâmetros Curriculares Nacionais. Afora as críticas que são feitas a este tipo de material, e não obstante as eventuais necessidades de revisão ideológica que este documento contempla, parece-nos que ele possui uma característica interessante, que é a de orientar o trabalho docente de forma mais geral, ou seja, não apresenta um programa rígido e inflexível a ser seguido em cada disciplina e em cada série.

O que percebemos é que nas realidades em que o material apostilado é adotado a função que deveria ser exercida pelos parâmetros curriculares nacionais passa a ser exercida pelas apostilas e justamente a característica de abertura dos PCN's é substituída pela rigidez da determinação de conteúdos fragmentados em unidades que devem ser cumpridas em espaço delimitado de tempo.

O interessante é que fica aparente nos relatos dos professores que esta característica limitadora do material apostilado é vista como um ponto positivo da implantação de sistemas apostilados em escolas públicas. Os professores aparentam crer que a seleção dos conteúdos e a determinação das atividades de sua sala de aula sejam atribuições de um ente externo à sala de aula. A seleção, organização e problematização dos conteúdos deixam de ser uma atividade eminentemente professoral.

Neste ponto podemos constatar mais uma característica que qualifica a apostila como uma mercadoria: sua fetichização. Usualmente fetiche 
é considerado como aquele objeto ao qual se atribui características, habilidades ou possibilidades que na realidade ele não possui ou não contempla. No entanto, cabe retomar as reflexões de Türcke (2010) sobre a natureza autorreferente da mercadoria.

Compreender que a mercadoria é autorreferente, significa ter a consciência de que o mercado traz o consumo como um fim em si mesmo. Consome-se por consumir, porque a promessa irrealizável da indústria cultural depende do fluxo do mercado para manter a ilusão de que em algum momento se realizará a satisfação do prometido.

Quando o mercado atinge um estágio que Türcke (2010, p. 241) denomina como "caminhar com seus próprios pés", o caráter fetichista da mercadoria passa a gerar a alienação, e a mercadoria "se transforma em algo para cuja causa se vive e, então, se obtém o sentido: esse é o credo do mercado" (TÜRCKE, p. 241, 2010).

Assim Türcke nos mostra como o mercado constitui-se no sucedâneo profano do sagrado, manifestando um novo credo, mas também nos possibilita a compreensão do processo que a introdução das apostilas tem causado no cotidiano educacional das escolas públicas.

A fetichização da apostila que possibilita que atribuições docentes sejam suplantadas pela sua utilização faz com que ela se torne, assim como as demais mercadorias, autorreferente e que possua um fim em si mesma; tornam-se não apenas um norte, mas a motivação, talvez única, fundamental das aulas.

Um aspecto que corrobora para a qualificação das apostilas como mercadoria é a publicidade existente em torno da contratação realizada pelas prefeituras municipais. Esta realidade foi constatada por Nicoleti (2009) que analisou aspectos da contratação de sistemas apostilados de ensino em município da região de São José do Rio Preto. ${ }^{7}$ Ao analisar o discurso da mídia local em relação aos sistemas apostilados de ensino, o pesquisador conclui que:

7 Cidade do Noroeste do Estado de São Paulo considerada polo regional de uma macrorregião. 
verificamos que os meios de comunicação são utilizados pelas prefeituras e pelos sistemas de ensino com o objetivo de empreenderem uma publicidade do produto "sistema apostilado". Com frequência, tais reportagens não propiciam ao leitor uma reflexão sobre as questões mais relevantes que envolvem a contratação desses sistemas, tais como a falta de consulta da opinião dos professores, durante o processo de escolha e de renovação com um sistema de ensino; o treinamento de professores para trabalharem com apostilas; a inexistência de avaliação do MEC sobre o material apostilado; o uso de recursos do FUNDEF com sistemas privados de ensino; entre outros (NICOLETI, 2009, p. 28).

Particularmente achamos bastante perigoso tratar questões pedagógicas por um viés estritamente mercadológico. Somos conscientes de que seria impossível, nos dias atuais, manter uma escola sem que haja o consumo de mercadorias, sejam elas culturais ou não. No entanto, o problema que detectamos é a centralidade do material apostilado em questões curriculares, relegando a uma mercadoria a determinação do itinerário educativo.

Com este processo, nos esquecemos de que "as disciplinas escolares são inseparáveis das finalidades educativas, no sentido amplo do termo 'escola'. E constituem 'um conjunto complexo que não se reduz aos ensinos explícitos e programados"” (JULIA, 2001, p. 33).

Neste ponto, podemos notar uma característica sintomática do consumo de mercadorias: a negação da dependência do produto. Se indagarmos um consumidor sobre o porquê da aquisição de um determinado produto supérfluo, ele dirá que decidiu proceder desta forma e muito dificilmente admitirá que se sentiu seduzido pelos apelos do mercado, ou que está reproduzindo de forma alienada um comportamento massificado.

O mesmo acontece com os docentes que, embora afirmem que um dos maiores benefícios da apostila é prescrever os conteúdos e as atividades das aulas, não admitem a utilização da apostila como diretriz única de suas aulas. A maioria dos docentes, ao serem indagados sobre 
a situação, afirma que os docentes, em geral, aferram-se à apostila como única fonte de informação, mas que no seu caso particular a apostila é apenas mais um dos recursos didáticos dos quais utiliza.

Cerca de $73 \%$ dos docentes afirmaram que, na ocasião do planejamento escolar, o material apostilado é considerado apenas mais um dos tantos recursos utilizados para determinar os conteúdos e objetivos a serem perseguidos durante o ano letivo. Este fato parece um indício de autonomia e criticidade; no entanto, outros dados contrastam com esta ideia e demonstram a centralidade do material apostilado na organização didática das escolas.

A utilização por $71 \%$ dos entrevistados da apostila em quatro ou mais dias letivos semanais e a recorrência das falas do questionário aberto - quando os professores foram novamente questionados sobre a ocasião do planejamento - de que o material apostilado é o mais importante estruturador da atividade de planejamento demonstram a adoção da apostila como parâmetro único da ação docente.

Cabe aqui ressaltar duas justificativas da frequente utilização da apostila, na opinião dos docentes. A primeira diz respeito à extensão do conteúdo da apostila e a segunda diz respeito à cobrança existente por parte dos superiores e dos pais de alunos para o cumprimento integral do programa da apostila.

Como já vimos, a reclamação da extensão do conteúdo não é exclusiva da realidade pública de ensino. Prado (2008) demonstrou-nos que os professores das escolas franqueadas também se sentem pressionados pelo programa do material apostilado que deve ser concluído em um curto espaço de tempo.

Já em relação à cobrança de pais e superiores, acreditamos que, no caso destes últimos, a pressão exercida se deva às exigências dos próprios sistemas municipais de ensino que visam garantir o sucesso de seu investimento, o que será revertido em uma publicidade positiva para o cenário político. Já no caso dos pais, acreditamos que tenha se disseminado a concepção, já exemplificada, de que os professores são incapazes de lecionar sem o auxílio do material apostilado. 
Somos, contudo, levados a acreditar que a necessidade de utilização contínua das apostilas não seja um acaso. Muito pelo contrário, existe uma tendência consciente por parte dos elaboradores do material apostilado em se ocupar o máximo possível do tempo de aula. Esta preocupação vem ao encontro do ideal da mercadoria de postular padrões de consumo.

No caso das apostilas, a manutenção de um padrão curricular reveste-se de um discurso que defende a utilização da apostila como um garantidor de que os alunos das mais diversas realidades recebam um mínimo comum que possibilite a qualidade do ensino.

No entanto, a proposição de um conteúdo extenso em volumes bimestrais visa a um efetivo controle do trabalho docente. Embora todas as editoras manifestem que o professor tem liberdade para aplicar as mudanças que acreditam necessárias, apresentam no mínimo quatro extensos volumes a serem vencidos em um ano e por meio de mecanismos de marketing induzem ao preenchimento do material como garantia do cumprimento de um mínimo curricular. Inclusive este fato está presente na fala dos professores que, ao serem indagados em questionário sobre as razões para a manutenção das apostilas nas escolas públicas, responderam que alguns profissionais não são bem formados e que o uso da apostila garantiria ao menos que os alunos percorressem os mesmos conteúdos, evitando que estes professores despreparados propusessem conteúdos desnecessários ou equivocados.

Este é também o discurso oficial que agrada bastante aos pais de alunos.

Aqui podemos atentar para mais um aspecto presente nas postulações Adorno e Horkheimer (1985), ao afirmarem que a Indústria Cultural não se acanha em explicitar seus objetivos e neste caso específico da educação não se inibe em utilizar o discurso da padronização. Algo veementemente combatido nas críticas à educação tradicional que é condenada por impor rígidos padrões, exigindo que os alunos decorem os preceitos disseminados pelo mestre que detêm o conhecimento, que é absoluto e inquestionável, passa a ser usado como slogan de campanha em prol à 
utilização de apostilas. Pois, qual seria o benefício da unificação curricular, senão a manutenção de um mínimo de conteúdos considerados absolutos e irrefutáveis?

O padrão que é veiculado como garantidor de qualidade segue o mesmo padrão cíclico dos demais bens culturais que se enquadram como produtos da indústria cultural. "Não somente os tipos das canções de sucesso, os astros, as novelas ressurgem ciclicamente com invariantes fixos, mas o conteúdo específico do espetáculo é ele próprio derivado deles e só varia na aparência" (ADORNO; HORKHEIMER, p. 117, 1985).

O mesmo ocorre com os materiais apostilados que, embora se aferrem a uma ideia de inovação educacional, seguem as mesmas orientações do livro didático, variando apenas na aparência (formatação e divisão bimestral dos fascículos) e na exacerbação dos mecanismos de controle.

Sentimo-nos seguros de que, para a maioria dos professores, as apostilas não diferem em sua essência dos livros didáticos, pois, sessenta e seis por cento dos docentes entrevistados responderam que em relação aos livros didáticos as apostilas podem ser consideradas mais do mesmo.

Embora haja esta semelhança entre os materiais didáticos, podemos afirmar que a apostila leva a cabo com mais eficiência o ideal padronizante da indústria cultural, principalmente pela cobrança existente pelos superiores imediatos, que agora se encontram bem próximos da instância do poder municipal, diferentemente de quando os docentes utilizam materiais do Programa Nacional do Livro Didático (PNLD) e os responsáveis diretos pela iniciativa encontram-se distantes em gabinetes da capital federal. Assim como pela cobrança dos pais que são seduzidos pelo discurso de que seus filhos estão sendo beneficiados com uma educação que antes era privilégio apenas da elite. E, por fim, pela sedução que o material exerce sobre os próprios professores efetuando promessas de facilidade pedagógica e orientação curricular.

O que nos preocupa, no entanto, é a difusão de uma lógica única de 
pensamento. ${ }^{8}$ Ao se impor um sistema apostilado, intenta-se que todos os professores procedam da mesma forma, independente de que escola ou sala estejam atuando. E caso essa premissa de seguir na íntegra o material seja acatada estaremos correndo o risco de desestimular outras abordagens sobre o mesmo assunto. A nosso ver, ao inibir outras abordagens sobre os conteúdos propostos, a apostila acaba por inviabilizar a compreensão da realidade, e os processos mecanicamente padronizados acabam por camuflar a contradição e a tolher o pensamento dialético.

Se a dialética entende a contradição como 'necessidade' pertencente à própria 'natureza do pensamento', assim o faz porque a contradição pertence à própria 'natureza do pensamento' [...] assim o faz porque a contradição pertence à própria natureza do objeto do pensamento, à realidade, onde a razão é ainda Anti-Razão, e o irracional ainda racional. Inversamente, toda a realidade estabelecida milita contra a lógica das contradições - favorece os modos de pensamento que conservam as formas de vida estabelecidas e os modos de comportamento que os reproduzem e aprimoram (MARCUSE, p. 141, 1978).

Marcuse, neste trecho, aborda justamente a discussão que Ramosde-Oliveira (2001) realiza ao mencionar a tensão existente no ato educativo entre a disseminação do conhecimento existente e a necessidade de abrir espaço para o novo.

É justamente esta a questão contemplada pela lógica dialética: somente operando dialeticamente é que o pensamento pode encontrar no campo da contradição ou da negação possibilidades diferentes e consequentemente promover a mudança.

Cabe ressaltar que a inviabilização do pensamento dialético protagonizada pela padronização imposta pelas apostilas não atua somente sobre os alunos, mas primeira e primordialmente sobre o professor, que passa

8 "A linguagem multidimensional é transformada em linguagem unidimensional, na qual significados diferentes e em conflito não mais se interpenetram, sendo mantidos separados; a dimensão histórica explosiva do significado é silenciada” (MARCUSE, 1978, p. 186). 
de profissional intelectual a profissional operário apenas dedicando-se ao cumprimento de esquemas predeterminados. A sala de aula torna-se linha de produção e os agentes envolvidos no processo educativo deixam de ser sujeitos transformadores da realidade para tornarem-se subprodutos da indústria cultural.

No entanto, é preciso retomar um aspecto recorrente na fala dos professores, que dizem não serem totalmente dependentes dos sistemas apostilados de ensino. Segundo os entrevistados, mesmo com a utilização diária das apostilas e com a extensão do conteúdo, é possível ter liberdade para propor outras atividades e complementar as falhas existentes no material apostilado.

A este respeito, cabe lembrar que em nosso primeiro questionário cem por cento dos entrevistados afirmaram utilizar outros materiais pedagógicos, sendo que a maioria relata que esta atitude é necessária devido às carências do material apostilado.

Em um primeiro momento, o fato de reconhecer falhas no material apostilado e de propor a utilização de outros materiais, pareceu-nos um forte indício de autonomia docente. E realmente estamos convencidos de que o ambiente de sala de aula é um espaço de atuação autônoma do professor. Não pretendemos postular que a ação docente independa de determinações ou imposições externas, somente estamos imbuídos de uma forte crença de que o momento da aula é eminentemente professoral e nesta experiência singular é possível romper algumas limitações e exercer uma atividade realmente livre.

O fato de os professores possuírem consciência das inconsistências do material apostilado e propor alternativas metodológicas, nos levou a necessidade de problematizar a questão por meio de perguntas abertas, para que houvesse oportunidade dos professores desenvolverem a ideia.

Neste momento pudemos notar que, embora efetuem algumas críticas ao material apostilado, os docentes acreditam que seu emprego é benéfico e este tipo de edição didática - apesar da insatisfação com alguns aspectos - possui uma privilegiada posição de centralidade nas escolas em que é utilizado, como já foi dito. 
Ao serem indagados sobre como era possível obter espaço para a utilização de materiais diversificados, os docentes alegaram que é possível conciliar a utilização de apostilas e o emprego de outras atividades. Somente um dos professores entrevistados condensou suas explicações na afirmativa de que o tempo para outras atividades é escasso. Os demais professores reiteram a possibilidade de se utilizar materiais variados.

No entanto, verificamos que na visão dos professores o complemento necessário resume-se em propor itens adicionais ou propiciar pré-requisitos à resolução dos exercícios. Ou seja, quando o professor acha que o conteúdo ou atividades contidos na apostila são insuficientes para fixar determinado conteúdo, são propostos exercícios ou textos adicionais, e quando se julga que os alunos ainda não possuem conhecimentos necessários para adentrar em tal tema, são fornecidos conceitos com o intuito de prepará-los para a utilização do material apostilado.

Outro aspecto considerado de autonomia pelos professores é a liberdade de dispor livremente da apostila durante as aulas semanais. $\mathrm{Ou}$ seja, não há um cronograma semanal rígido para a execução da apostila, desde que seja cumprida dentro do bimestre, haja vista que são quatro volumes anuais a serem cobertos em cada disciplina.

Constatamos, portanto, que a apostila é quem dita a metodologia e sequência dos conteúdos. O material didático acaba por funcionar como um itinerário a ser seguido e o professor contenta-se em determinar os pontos de parada, descanso, alimentação e reabastecimento. No entanto, o docente parece permanecer sempre fiel ao percurso partindo sempre do mesmo destino e almejando sempre o mesmo ponto de chegada.

Dessa forma, podemos constatar que o intuito, das autoridades educacionais de padronizar o processo de ensino nas diferentes unidades da rede está sendo realizado com sucesso. A nosso ver, embora possuam algum grau de liberdade ao utilizar as apostilas, não podemos classificar a atividade docente frente ao material apostilado como autônoma.

Para que a atividade docente pudesse ser considerada realmente 
autônoma, seria necessária uma atividade de crítica imanente perante aos sistemas apostilados de ensino.

Trata-se de compreender como o objeto, de uma forma que não deixa de nos lembrar Hegel na Fenomenologia do Espírito, já traz dentro de si sua própria medida de avaliação, isto no interior de uma relação tensa consigo mesmo. A medida já está presente no objeto e pode ser identificada à condição de sermos atentos aos antagonismos que constituem o objeto e que o colocam em movimento (SAFATLE, p. 25, 2009).

Criticar de forma imanente a utilização das apostilas e verificar a medida contida nelas mesmas de sua avaliação, minimamente conduziria ao desvelamento dos processos de padronização existentes e proporcionaria processos de subversão em que os docentes ousassem proceder de outra maneira que não fosse a apresentação de temas propostos por um material e a consequente resolução de exercícios.

Mas os docentes parecem achar bastante cômoda a adoção das apostilas propiciando-lhes diretrizes claras a serem seguidas. Neste ponto é importante ressaltar que ao atar-se à orientação curricular das apostilas, o docente não está apenas abrindo mão de sua atribuição, mas está também negando o potencial negativo do seu exercício profissional.

Com esta pesquisa notamos que os professores não se sentem seguros em discutir o currículo das séries em que lecionam e, para nós, isto é forte indício da perda do potencial negativo da razão. Notamos também uma forte ideia, entre os docentes, de que existe um percurso acadêmico a seguir e que este caminho pode ser cartografado, mas não se sentem habilitados para traçá-lo e as apostilas seriam o mapa que poderia guiar-lhes com sucesso. Ao adotar esta postura, parece que os docentes acreditam na existência de algumas verdades que manteriam a ordem necessária para a perpetuação do conhecimento e da sociedade.

O que parece desagradável e desordeiro do ponto de vista lógico, bem pode conter os elementos agradáveis de uma ordem diferente, 
podendo ser, assim, parte do material de que são feitos os conceitos filosóficos. Nem o mais refinado senso estético nem o conceito filosófico mais exato são imunes à história. Elementos desordeiros entram nos objetos mais puros do pensamento. Estão também destacados do terreno social, e os conteúdos dos quais se abstrai guiam a abstração (MARCUSE, 1978, p. 202).

Pretendemos apenas alertar para o fato de que ao mesmo tempo em que os docentes alegam ter uma postura autônoma diante dos materiais apostilados, remetem a estes uma posição central e deixam transparecer que o material dita as regras no lugar do próprio professor. Relembremos apenas que o processo onde o objeto passa a dominar seu criador é um exemplo de alienação.

Portanto, esta alienação propiciada pela apostila faz com que o docente seja controlado por um objeto ao invés de controlá-lo. A ferramenta deixa de ser potencializadora da ação humana para tornar-se a sua determinante. Os aspectos subjetivos dão lugar à aplicabilidade estritamente prática de um ou outro conceito. Esse é para nós um exemplo efetivo de disseminação da razão instrumental no cotidiano educacional.

Quando tomamos as postulações de Marcuse a respeito da potencialidade de reorganização dos elementos desordeiros, não estamos nos referindo à disciplina da sala de aula ou a falácia de alguns discursos pedagógicos distorcidos que apregoam que uma aula criativa deve ser barulhenta e desorganizada. Queremos apenas atentar para o fato que o elemento desordeiro é aquele que subverte a ordem de pensamento estabelecido. Atentemos para o fato de que a determinação prévia e externa das atividades a todas as escolas de uma rede de ensino específica ou até mesmo a escola de diversas redes municipais de ensino, faz com que seja disseminado um padrão de ensino. Todos são induzidos a aprender as mesmas coisas, na mesma sequência e pelo mesmo procedimento. Mais que garantir um mínimo de conhecimentos necessários à socialização dos educandos, este procedimento impede que a coisas sejam feitas de uma maneira diferente. 
Desordenar, portanto, nada mais seria que fazer diferente, ousar não ser igual, negar o estabelecido, experimentar. Subversão não significa baderna e transtorno. Subverter em nossa sociedade pode ser apenas negar os padrões do mercado.

O que os docentes consideram autonomia pode ser bem exemplificado nas palavras de um dos entrevistados ao ser indagado sobre sua autonomia quanto à seleção de conteúdos em seu dia a dia: "Na escola em que trabalho e na rede municipal de ensino também, os professores tem autonomia para escolher os dias e como utilizar o sistema apostilado, na escolha de atividades extras, o professor fica livre, sem cobranças para trabalhar" (Professor 7).

O simples fato de decidir se a interpretação do texto ocupará o tempo de uma ou duas aulas, ou ainda se será necessário sugerir ou não a procura de mais palavras no dicionário do que as propostas pelo vocabulário do texto, parece ser visto como indício de autonomia.

Acreditamos que a autonomia docente vai além destas atividades que se aproximam muito mais de uma experiência organizacional do que de um efetivo exercício intelectual. O professor como profissional da educação deveria refletir não apenas sobre os conteúdos, mas também sobre os métodos de ensino e sobre as especificidades dos educandos.

Assim como o pensamento autônomo é bidimensional, a educação autônoma também o é, pois de um lado deve contemplar os saberes já construídos e que tornam nossa vida mais cômoda, e de outro sempre instigar a negação da ordem estabelecida para procurar novas formas de conhecer.

Ao se aferrar a um itinerário prescrito, a educação menospreza a complexidade da realidade. Ou será que já chegamos ao momento histórico em que devemos crer que tudo que havia para ser conhecido já foi descoberto? Será que nem um dos nossos educandos poderá mudar a compreensão do cosmo como fez Galileu? Ou inaugurar uma nova forma de compreensão da mente humana como fez Freud?

Estaríamos, portanto, livres de rupturas; já teríamos chegado à compreensão da realidade tal e qual em sua verdadeira essência. Particu- 
larmente acreditamos que ainda estamos distantes dessa realização - se é que algum dia ela será possível.

Para finalizar esta nossa problematização, gostaríamos de atentar para um último fato, já mencionado, mas que precisa ser enfatizado: o fato da má formação docente ser tomada como justificativa para a adoção de apostilas em escolas públicas.

Não é objetivo deste trabalho e não haveria disponibilidade de tempo para discorrer a contento sobre a problemática da formação docente. Portanto, não iremos julgar o mérito dos cursos de formação de professores em nosso País, tampouco discutir os determinantes econômicos e sociais que dificultam a qualificação da profissão docente propiciando sua precarização. Contudo, faz-se necessário atentar que o argumento revelado pelos docentes de que a apostila garantiria que professores menos competentes não cometeriam grandes equívocos se seguissem à risca a orientação do material apostilado é bastante falho.

A nosso ver, postular que um manual didático é capaz de possibilitar que um docente aja de uma forma minimamente competente, nos remete à fala de Lemov (2011) de que é possível se elencar técnicas garantidoras de sucesso. Ou ainda pior: nos faria concordar com a opinião de Castro (2011) que compara os materiais didáticos a manuais de instrução de aeronaves.

O problema da formação docente só poderá ser resolvido por meio da atividade formativa, acadêmica ou continuada; jamais por manuais. O professor malformado é aquele que não possui subsídios suficientes para refletir sobre a complexidade do ato educativo, faltando-lhe também consistência conceitual para lidar com os conteúdos de sua disciplina. Não conseguimos, portanto, visualizar a forma pela qual as apostilas sanariam estes aspectos deficitários.

Dessa forma, o argumento apresentado não pode ser levado a cabo.

A consciência é "não-livre" no quanto é determinada pelas exigências e pelos interesses da sociedade estabelecida; no quanto a sociedade estabelecida é irracional, a consciência se torna livre para a mais 
elevada racionalidade histórica somente na luta contra a sociedade estabelecida. A verdade e a liberdade do pensamento negativo têm sua base e sua razão nessa luta. Assim, segundo Marx, o proletariado é a força histórica libertadora somente como força revolucionária; a negação determinada do capitalismo ocorre se e quando o proletariado se torna cônscio de si e dos processos e condições que formam essa sociedade. Essa consciência é tanto, um requisito como um elemento da prática negativa. Esse 'se' é essencial ao progresso histórico - é o elemento de liberdade (e oportunidade!) que abre as possibilidades de conquistar a necessidade dos fatos dados. Sem ele, a história retorna a escuridão da natureza inconquistada (MARCUSE, 1978, p. 207).

Com esta pesquisa, somos levados a acreditar que a exemplo da sociedade a docência também é administrada se assemelhando à atividade proletária de chão de fábrica. Dessa forma, assim como Marcuse (1978), cremos que a exigência necessária para o exercício livre da profissão é o professor tomar consciência de si próprio e dos mecanismos de controle que incidem sobre sua atividade.

As apostilas enquanto mercadorias tornam-se fetiches que se apropriam de tarefas que deveriam ser delegadas aos educadores - isto, porém, não significa o fim da autorreflexão crítica em educação. Indica antes que devemos refletir sobre esta prática e procurar meios de recuperar a consciência docente, que propiciará a experiência do pensamento negativo, que, por sua vez, desvendará novas possibilidades.

\section{Considerações finais}

Este trabalho, embora não tenha esgotado a temática abordada, conseguiu evidenciar alguns aspectos importantes para a compreensão da realidade educacional das escolas públicas brasileiras. Apontaremos algumas constatações que obtivemos durante a pesquisa.

O primeiro aspecto é o de que a adoção de Sistemas Apostilados de Ensino é uma atitude que se fortalece devido à preocupação operacional 
de atendimento à demanda educacional, que remete à questão da eficácia das tecnologias educacionais. Assim, podemos concluir que esta preocupação acaba por legitimar ações que visam a padronização da conduta e, por conseguinte, ao controle e cerceamento da liberdade de pensamento, ou seja, de autorreflexão. Foi evidenciado ainda que uma educação rigidamente controlada pode ser útil ao desenvolvimento social, pois possibilita o conhecimento técnico necessário a produção e consumo de mercadorias.

Dentre as teorias que discutem os mecanismos sociais de controle, constatamos que a atualidade dos conceitos frankfurtianos, em especial aqueles evidenciados por Hebert Marcuse, nos possibilitam a melhor compreensão de como a sociedade industrial utiliza-se da sedução tecnológica para efetivar o domínio social por meio da transformação de todos os sujeitos em consumidores passivos.

Não obstante, a mudança técnica e o crescente número de equipamentos tecnológicos que passam a ser utilizados cotidianamente, pôde ser verificado que as assertivas de Marcuse a respeito da sociedade industrial permanecem válidas e demonstram que embora hightech, a lógica dominante ainda é pautada na instrumentalização da razão.

Reiteramos o fato de que os mecanismos de controle se tornam mais sutis, pois são eufemizados pelo crescente aumento no padrão de vida, pela propensão do ser humano a aderir à utilização de objetos tecnológicos e pela fetichização de mercadorias. É, portanto, para nós, clara a constatação de que nossa sociedade se configura como uma sociedade administrada e que quanto maior o desenvolvimento tecnológico maior a possibilidade de se administrar os indivíduos, controlando-os por meio da imposição de padrões de consumo.

Dessa forma, cabe ressaltar que a inserção dos sistemas apostilados de ensino em escolas públicas ocorre em um cenário de administração social, que possui no mercado e no consumo de mercadorias seu principal mecanismo de dominação. Neste ponto, cabe ressaltar que as apostilas também são mercadorias e, portanto, já estão de antemão inseridas em uma dinâmica de padronização e controle. 
Em relação aos dados obtidos na pesquisa com os docentes podemos evidenciar alguns pontos importantes. Um deles é a avaliação docente sobre a qualidade do material apostilado. É bastante interessante notar que na opinião da maioria dos professores abordados, as apostilas são apenas razoáveis. Assim podemos dizer que para os profissionais que utilizam estas edições didáticas, elas são consideradas falhas em muitos aspectos. Porém, mesmo com esta constatação, os docentes defendem a utilização do material apostilado em escolas públicas. Ao verificar o porquê desta contradição constatamos que os entrevistados se sentem beneficiados pelo uso da apostila.

Dessa forma, a principal constatação deste trabalho não é sobre a qualidade das apostilas, mas a percepção de a atividade docente ter perdido seu potencial reflexivo e é neste sentido que afirmamos que a atividade docente se assemelha a do operário. Como o trabalhador de chão de fábrica, o docente apenas realiza um determinado procedimento em uma grande linha de produção. Deve apenas reproduzir as "sugestões" ditadas pelo material didático para que seus alunos tenham sucesso. É claro que para isso deverá atentar-se para as características do equipamento (apostila) e se necessário poderá recorrer ao manual de instruções (manual do professor) ou ao suporte técnico (assessoria pedagógica) para sanar qualquer mau funcionamento.

Para os docentes constatamos que esta situação é confortável, pois estão a consumir um material agradável que lhes possibilita o exercício da inércia intelectual. Não pretendemos dizer que os professores se encontram imobilizados, mas sim que permanecem em uma trajetória retilínea, sem alterações de curso (como nos indica a compreensão física de inércia), seguindo incansavelmente o trajeto predeterminado. Ou como ainda pode-se afirmar, mais próximos da minoridade do que de uma prática que preconiza a busca por uma educação emancipadora.

Essa sensação deve-se à ideia de que o material apostilado seria o responsável pela determinação curricular, garantindo que os conteúdos corretos sejam selecionados, organizados, problematizados e fixados na 
etapa correta do processo ensino aprendizagem. Desse modo, uma consideração importantíssima que obtivemos com esta pesquisa é a de que os docentes acreditam que a atividade docente em sala de aula está dissociada da atividade de reflexão curricular e acabam por delegar à apostila a função de direcionar os caminhos a serem seguidos em suas aulas.

Pudemos notar que as apostilas ocupam o lugar das diretrizes curriculares nacionais, no entanto de forma mais determinista e menos suscetível à contextualização. Esse fato nos revela que a natureza do emprego de materiais apostilados é fetichizada, ou seja, a atividade de seleção e organização de conteúdos escolares, que é uma atividade eminentemente professoral, passa a ser incumbência de um objeto incapaz de realizá-la a contento e, portanto, a constituição de um fetiche.

Assim, vemos que a apostila fetichizada torna-se autorreferente e passando a ter um fim em si mesma pode seguramente ser classificada como uma mercadoria. Na esteira destas conclusões vimos que os docentes mesmo submetendo-se à utilização das apostilas se acreditam autônomos por acreditarem ter autonomia para gerenciá-las.

Todavia, constatamos que a flexibilidade que os profissionais alegam possuir restringe-se à determinação da dosagem dos conteúdos e atividades que devem ser trabalhados no bimestre letivo. Isto nos leva a concluir que não existe um exercício realmente autônomo da docência, pois se inviabiliza a possibilidade de experimentar outros caminhos. A contextualização do material apostilado que é descrita pelos professores se limita a complementar as atividades propostas ou a propiciar pré-requisitos para o efetivo preenchimento do material.

A situação torna-se problemática à medida que compreendemos que não experimentar outros caminhos pode significar aceitar irrefletidamente a ordem estabelecida. Aceitar a ordem estabelecida significa a impossibilidade do exercício negativo do pensamento reflexivo. Ao procederem dessa forma, os docentes perdem a potencial reflexivo da profissão que passa a assemelhar-se com os demais ramos de atividade da Indústria Cultural. Ou seja, a escola que deveria ser um ambiente de 
promoção da cultura e do conhecimento se parece mais com uma linha de montagem que deve ter sua engrenagem constantemente lubrificada para que o padrão de produção não seja afetado.

Assim, contatamos que nossa hipótese inicial de que a docência no contexto de utilização de mercadorias como os sistemas apostilados de ensino torna-se uma atividade administrada se confirmou. No entanto, não encaramos tal fato como o sepultamento do potencial crítico da docência. Pelo contrário, nos leva a acreditar na eminente necessidade de se tomar consciência dos mecanismos de controle engendrados pelas mercadorias que consumimos diariamente. Gostaríamos ainda de atentar para a justificativa dos docentes de que as apostilas são uma alternativa a má formação docente.

A este respeito, verificamos que o emprego de materiais didáticos como se fossem manuais de instrução, não pode ser eficaz na resolução de problemas como os da formação docente. Este fato reitera a certeza de que a razão instrumental já se instalou no universo educacional e que entre os profissionais da Educação, a exemplo do educador americano Doug Lemov (2011), acredita-se que uma educação de qualidade está pautada no emprego de determinadas técnicas previamente ensaiadas.

Outro fato interessante é o de que na fala dos professores podemos verificar que o material apostilado sempre é visto como um benefício para o professor e não para o aluno. Parece-nos que os professores, embora saibam das deficiências do material apostilado e da sua eminente semelhança com outros materiais didáticos como o livro didático, sentem-se beneficiados por não precisarem dispensar parte valiosa de seu tempo com a organização curricular. Dessa forma, uma das mais importantes constatações que realizamos com este trabalho é a de que o maior problema não é o emprego da apostila como material didático, haja vista que a educação brasileira sempre se pautou no consumo de edições didáticas. Contudo, em especial no caso da apostila notamos que lhe é conferida uma centralidade e o que era para ser apenas uma ferramenta didática passa a ser a determinante de padrões do conhecimento. 
Acreditamos, portanto, que a maior constatação deste trabalho é a de que a docência se torna administrada por permitir que as atividades docentes sejam exteriormente determinadas, dissociando a atividade docente da atividade reflexiva, o que a nosso ver é extremamente prejudicial por fazer da sala de aula um local de cultura enlatada, pré-formatada e, consequentemente, de disseminação da semicultura. ${ }^{9}$ Se não possibilitarmos o exercício do pensamento negativo, estaremos fadados à perpetuação da exploração social e da disseminação da semiformação.

É de grande urgência o apontamento e a reflexão destes fatos para que todos nós profissionais envolvidos com a educação rompamos as barreiras da falsa consciência produzida pela realidade sedutora da Indústria Cultural, para podermos conduzir nossos alunos através das cortinas da aparência, abrindo espaço para o que não é, para uma outra ordem, enfim possibilitando que nossos educandos possam dar continuidade no processo de evolução do conhecimento humano por meio do único modo que a ciência conseguiu visualizar até o presente momento: a ruptura.

\section{Referências}

ADORNO, Theodor W. A indústria cultural. In: COHN, G. (Org.) Comunicação e indústria cultural: leituras de análise dos meios de comunicação na sociedade contemporânea e das manifestações da opinião pública, propaganda e "cultura de massa" nessa sociedade 4. ed. São Paulo: Nacional, 1987.

9 A semiformação cultural caracteriza-se justamente por seu fechamento, por seu caráter de conclusão: está feita e não admite questionamentos. E cultura que não se renova é cultura que se estiola. Eis o caráter fundamental da semiformação cultural: ela não se autoquestiona, ou seja, não permite o funcionamento da autorreflexão crítica! Esse tipo de cultura é a morte da cultura em sua dimensão emancipatória, não sua aparência. Por ser cultura às metades, está entorpecida e impede o florescer da cultura de corpo inteiro, a cultura que conjuga e harmoniza as dimensões instrumentais e emancipatórias num movimento contínuo (RAMOS-DE-OLIVEIRA, 2001, p. 26). 
; HORKHEIMER, Max. Dialética do esclarecimento. Tradução de GuidoAntonio de Almeida. Rio de Janeiro: Zahar Editora, 1985.

AFONSO, Emília Gallego. Despalavra e moralidade na literatura infantil. In: SERRA, Elizabeth D’Angelo (Org). Ética, estética e afeto na literatura para crianças. São Paulo, Global, 2001.

CARNOY, Martin. A vantagem acadêmica de Cuba: por que seus alunos vão melhor na escola. São Paulo: Ediouro, 2009.

CASTRO, Claudio de Moura. A arte da improvisação. Revista Veja. Edição 2199, ano 44, n. 2, Editora Abril: São Paulo, 12 de janeiro de 2011.

JULIA, Dominique. A cultura escolar como objeto histórico. Revista Brasileira de História da Educação, Maringá, v. 1, p. 9-43, jul./dez. 2001.

KANT, Immanuel. Resposta à pergunta: Que é "esclarecimento"? (Aufklãrung). In: . Textos seletos. Tradução de Floriano de Sousa Fernandes; Raimundo Vier. 3. ed. Petrópolis: Vozes, 2005.

LEMOV, Doug. Aula nota 10: 49 técnicas para ser um professor campeão de audiência. Tradução de Leda Beck. São Paulo: Da Boa Prosa; Fundação Leman, 2011.

MARCUSE, Herbert. A ideologia da sociedade industrial. Tradução de Giasone Rebuá. 6. ed. Rio de Janeiro: Zahar Editores, 1978.

. Eros e civilização. Tradução de Álvaro Cabral. São Paulo: Círculo do Livro S/A, 1966.

. Sobre Max Weber. In: WEBER, Max. O político e o cientista, 2. ed. Tradução de Carlos Griffo. Lisboa: Presença. 1973.

NICOLETI, João Ernesto. Ensino apostila na escola pública: tendência crescente nos municípios da região de São José do Rio Preto - SP. 2009. 97f. Dissertação (Mestrado em Educação Escolar) - Faculdade de Ci- 
ências e Letras, Universidade Estadual Paulista Júlio Mesquita Filho, Araraquara, 2009.

PRADO, Jefferson Antonio do. A compreensão da atividade pedagógica configurada em uma rede de inter-relações: Franquia Escolar. Rio Claro: UNESP, Dissertação de Mestrado, 2008.

RAMOS-DE-OLIVEIRA, Newton. Do ato de ensinar numa sociedade administrada. Caderno CEDES Indústria Cultural e Educação, Campinas, n. 54, p. $19-27,2001$.

SAFATLE, Vladimir. Adorno e a crítica da cultura como estratégia da crítica da razão. Artefilosofia. Ouro Preto, n. 7, p. 21-30, Out. 2009.

SKINNER, Burrhus Frederic. Tecnologia do ensino. Tradução de Rodolpho Azzi. São Paulo: EdUSP, 1972.

ZUIN, Antonio Álvaro Soares. Sobre a atualidade do conceito de indústria cultural. Caderno CEDES Indústria Cultural e Educação, Campinas, n. 54, p. 9-27, 2001.

Data de registro: 10/06/2014

Data de aceite: 06/05/2015 